\title{
Overexpression of CD105 in rat myoblasts: Role of CD105 in cell attachment, spreading and survival
}

\author{
BAOQIANG GUO ${ }^{1}$, PAUL ROONEY ${ }^{1}$, MARK SLEVIN ${ }^{2}$, CHENGGANG LI $^{1}$, SUDEEP PARAMESHWAR ${ }^{1}$, \\ DONGHUI LIU ${ }^{1}$, PAT KUMAR ${ }^{2}$, CARMELO BERNABEU ${ }^{3}$ and SHANT KUMAR ${ }^{1,4}$ \\ ${ }^{1}$ Laboratory Medicine Academic Group, The Medical School, University of Manchester, Oxford Road, \\ Manchester, M13 9PT; ${ }^{2}$ Manchester Metropolitan University, All Saints, Manchester, M15 6BH, UK; \\ ${ }^{3}$ Centro de Investigaciones Biologicas, CSIC, Madrid, Spain; ${ }^{4}$ Christie Hospital, Manchester, UK
}

Received January 9, 2004; Accepted March 3, 2004

\begin{abstract}
CD105 is a receptor for transforming growth factor- $\beta$ but it is also considered to be involved in cellular functions such as cell adhesion and migration. Using CD105 transfected rat myoblasts, we have investigated the role of CD105 in cell adhesion, spreading, growth and migration. CD105 transfected myoblasts expressed abundant CD105, which was preferentially located within focal adhesion sites. These cells took on a bipolar morphology whereas mock cells remained polygonal or rounded, and when wounded, CD105 expressing cells realigned their long axis prior to migrating and migrated as a cohort of cells. CD105 expression promoted cellular attachment, spreading, survival and growth in serum-free conditions and each of these parameters could be inhibited by a RGD-containing peptide but not a RAD-containing peptide. Mock-transfected cells could not attach, spread or grow under these conditions. Attachment, spreading and growth in CD105 expressing cells could be promoted by the addition of a monoclonal antibody against CD105. Expression of CD105 resulted in the phosphorylation of JNK1 but had no effect on B1 integrin expression. From this preliminary study, we conclude that in addition to acting as a transforming growth factor- $\beta$ receptor, CD105 has an important role in cell adhesion, migration and survival.
\end{abstract}

\section{Introduction}

CD105 (endoglin) is an angiogenic mediator predominately expressed by endothelial cells (EC) but also by activated macrophages, some stromal cells and vascular smooth muscle cells (1-5). It is located within the cell membrane as a $180 \mathrm{kDa}$ homodimeric transmembrane glycoprotein whose external domain binds transforming growth factor- $\beta$ (TGFß) isoforms 1

Correspondence to: Dr B. Guo, Laboratory Medicine Academic Group, The Medical School, Stopford Building, University of Manchester, Oxford Road, Manchester, M13 9PT, UK

E-mail: baoqiang.guo@man.ac.uk

Key words: CD105, cell survival, cell signaling and 3 with a high affinity and whose transmembrane and intracellular domains share a $71 \%$ sequence homology to betaglycan (6). CD105 has been linked with cell migration, e.g. it is expressed during the transition from polarised undifferentiated to non-polarised intermediate cytotrophoblasts as the cells align in columns to invade the uterus (7). CD105 production in cytotrophoblasts occurs in parallel with the expression of the fibronectin receptor, $\alpha 5 \beta 1$ integrin and evidence suggests that there may be an interaction between the two.

CD105 plays important roles in cardiovascular development. It is markedly up-regulated in endocardial cushion mesenchyme during valve formation in human embryos at 5-8 weeks of gestation (8), and is highly expressed on ECs during angiogenesis (9-14). The importance of CD105 expression in vasculogenesis can also be seen in CD105 knockout mice where the animals die in utero at 10-11.5 days because of abnormal blood vessel formation $(4,15)$. CD105 is also the target gene for the human, dominant vascular disorder hereditary haemorrhagic telangiectasia 1 (16).

How CD105 functions in these diverse physiological and pathological processes is not fully understood. Although it is an important component of the TGF $\beta$ receptor signalling complex, it is unlikely that its sole function is to bind TGFB. Indeed, even though there is a 100 -fold excess of CD105 to the TGFB receptor II on the surface of normal ECs, only $1 \%$ of the total CD105 molecules are able to bind TGFß1 (6). It may act via interaction with other membrane receptor proteins, such as TGFß receptors or directly associate with intracellular proteins such as focal adhesion kinase (FAK) or adaptor proteins. Overexpression of CD105 in rat myoblasts and myelomonocytic cells substantially decreases the ability of TGFß1 to inhibit cellular proliferation and to stimulate fibronectin and plasminogen activator inhibitor 1 synthesis, indicating that CD105 can modulate specific responses to TGFß1 $(1,17)$. CD105 is a RGD-containing integral membrane protein and as such it may act as a counter-receptor for one or more members of the integrin family (18). When human umbilical vein EC (HUVEC) monolayers were pre-treated with monoclonal antibodies (mAbs) to CD105, a 5- to 10-fold increase in adhesion of non-adherent U937 cells to HUVECs was observed (18). A fibronectin hexapeptide, containing RGD, 
but not the corresponding RGE control peptide, antagonised the enhancement of adhesion induced by the CD105 mAbs, suggesting that the signal is triggered by CD105 through its RGD structure (18). Therefore, CD105 may act through its RGD or other structure(s) to affect cell attachment, spreading and migration.

Here, utilising CD105 transfected rat myoblasts, we demonstrate that CD105 is preferentially localised at focal adhesion sites. CD105 expression resulted in morphological changes and directional cell movement. Furthermore, in the absence of serum, CD105 promoted cell spreading. Unexpectedly, anti-CD105 mAb, E9, markedly enhanced cell spreading, which could be blocked by RGD but not RADcontaining peptides. Lastly, overexpression of CD105 led to phosphorylation of JNK1. We propose that the cell survival mediated by CD105 works through the integrin related FAK/ Cas/Crk/Rac/MKK4/JNK pathway.

\section{Materials and methods}

Stable rat myoblast transfectants. Rat myoblast transfectants, expressing CD105 were established by co-transfecting PcEXV Endo S and psV2neo as described by Letamendia et al (17). Transfection with psV2neo alone yielded cells which did not express CD105 - mock transfectants (19). All transfectants were maintained in a humidified incubator in $5 \% \mathrm{CO}_{2}$ at $37^{\circ} \mathrm{C}$ in DMEM (Sigma) supplemented with $10 \%$ foetal bovine serum (FBS, Gibco BRL), and $400 \mu \mathrm{g} / \mathrm{ml} \mathrm{G418} \mathrm{(Sigma)} \mathrm{unless}$ stated below. Media were changed every third day.

Human dermal microvascular endothelial cells (HDMECs). HDMECs (Clonetics, San Diego, CA) were cultured in medium MCDB 131 supplemented with $10 \%$ FBS, $100 \mu \mathrm{g} / \mathrm{ml}$ penicillin, $100 \mu \mathrm{g} / \mathrm{ml}$ streptomycin, $2 \mathrm{mM}$ L-glutamine (all Gibco) and $10 \mathrm{ng} / \mathrm{ml}$ epithelial growth factor (Sigma). Cells were maintained at $37^{\circ} \mathrm{C}$ in a humidified incubator at $5 \%$ $\mathrm{CO}_{2}$ as above.

Wounding assays for cell migration. Mock and CD105 expressing rat myoblast transfectants were seeded at $5 \times 10^{5}$ cells/well in 12-well plates. This concentration produced rapid confluency and after $24 \mathrm{~h}$, the confluent cell monolayer was wounded with a $1 \mathrm{ml}$ (blue) plastic pipette tip, generating a linear wound, $\sim 15$ cells wide. The entire cultures were rinsed 3 times with PBS to remove cellular debris; fresh medium was added and they were cultured under standard conditions. The wound areas were inspected regularly during the next $24 \mathrm{~h}$ under phase contrast microscopy and photomicrographs were taken using a Leitz Diavert microscope equipped with a Wild Photoautomat MPS45 system. The distance and direction of cell movement and the morphology of the cells were evaluated.

Cell attachment and spreading assay. The effect of CD105 on cell attachment and spreading was evaluated by inoculating cells onto tissue culture dishes for 2 or $24 \mathrm{~h}$ respectively.

Mock and CD105 expressing rat myoblast transfectants were seeded in 12-well plates and when $\sim 60 \%$ confluent were harvested in one of three ways: i) scraping followed by repeated pipetting of the cells (20); ii) treatment with EDTA $(0.02 \%$, Sigma $) /$ trypsin $(0.05 \%$, Gibco $)$ solution followed by washing in $0.2 \%$ soybean trypsin inhibitor; or iii) treatment with EDTA alone. After harvest the cells were plated out in 96-well plates at $10^{4}$ cells/well for cell attachment or in 12-well plates for cell spreading.

To examine the effect of the anti-CD105 mAb E9 on cell attachment, spreading and proliferation, mock and CD105 expressing rat myoblasts were inoculated into wells in serumfree medium already supplemented with anti-CD105 mAb E9 (1 or $10 \mu \mathrm{g} / \mathrm{ml}$ ) (12) or control mAb of the same isotype as mAb E9 (Santa Cruz Biotechnology, Inc.). Cell morphology was recorded by examination under a phase contrast microscope for $24 \mathrm{~h}$.

In blocking assays for attachment and spreading, a polypeptide RGD sequence containing (GLY-ARG-GLY-ASPSER-PRO-LYS) (Sigma), or a RGD mutant polypeptide - RAD sequence containing (GLY-ARG-ALA-ASP-SER-PRO-LYS) (Sigma) was added into the medium.

Cells were fixed for 30 min with $100 \%$ methanol (BDH) and then washed once with PBS. The total number of cells attached and the percentage of spread cells were counted in at least three random fields, in each of 3 wells, using the $\times 10$ objective on the phase contrast microscope. A spread cell was characterised as one having a clearly visible ring of cytoplasm around the nucleus.

Western blot analysis. Mock transfected and CD105 expressing rat myoblasts were grown to near confluence as described above and harvested in EDTA/trypsin in PBS, washed with $\mathrm{PBS}$ and pelleted by centrifugation. For CD105 analysis, $10 \mu \mathrm{l}$ total cell lysis buffer [containing $20 \mathrm{mM}$ Tris-HCl, $\mathrm{pH} 7.5$, $150 \mathrm{mM} \mathrm{NaCl}, 10 \%$ (v/v) glycerol, $1 \%$ Triton X-100 (all $\mathrm{BDH}), 2$ mM EDTA, $100 \mu \mathrm{M} \mathrm{Na}_{3} \mathrm{VO}_{4}, 1 \mathrm{mM}$ PMSF, $10 \mu \mathrm{g} / \mathrm{ml}$ each of aprotinin, leupeptin and pepstatin (all Sigma)] was added to $2 \times 10^{6}$ cells. For p-JNK analysis, myoblasts were cultured in serum-free medium for $24 \mathrm{~h}$ before adding $100 \mu \mathrm{l}$ total lysis buffer.

The protein concentration in the cell lysates was measured by a Bio-Rad protein assay as per the manufacturer's instructions and $50 \mu \mathrm{g}$ of protein was subjected to SDS-PAGE on $7.5 \%$ polyacrylamide gels under reducing (for P-JNK) or non-reducing (for CD105) conditions. Proteins were electrophoretically transferred to PVDF membrane (Millipore Corp., Bedford, MA). The blots were blocked with PBS-Tween buffer containing $5 \%$ non-fat milk powder for $2 \mathrm{~h}$ and then incubated with anti-CD105 mAb E9 or anti-p-JNK mAb Sc6254 (0.2 $\mu \mathrm{g}$ / $\mathrm{ml}$, Santa Cruz Biotechnology, Inc.) at $4^{\circ} \mathrm{C}$ overnight, followed by an HRP-conjugated rabbit anti-mouse IgG (1:2000 dilution, Dako) at room temperature. The membrane was developed using an enhanced chemiluminescence (ECL) detection system (Amersham Pharmacia Biotech).

Evaluation of loading controls was performed by stripping the membrane with $2 \% 2$-mercaptoethanol-PBS solution, and incubating the blots with primary rabbit anti-total JNK Ab $(0.2 \mu \mathrm{g} / \mathrm{ml}, \mathrm{Sc} 571$, Santa Cruz Biotechnology, Inc.) or rabbit anti-actin $\mathrm{Ab}(0.2 \mu \mathrm{g} / \mathrm{ml}$, Sigma), acting as loading controls for p-JNK and CD105 respectively and then incubating with the HRP-conjugated goat anti-rabbit Ab, prior to ECL.

Flow cytometry analysis. Cell surface expression of $\beta 1$ integrin on transfected rat myoblasts was quantified by flow cytometry 

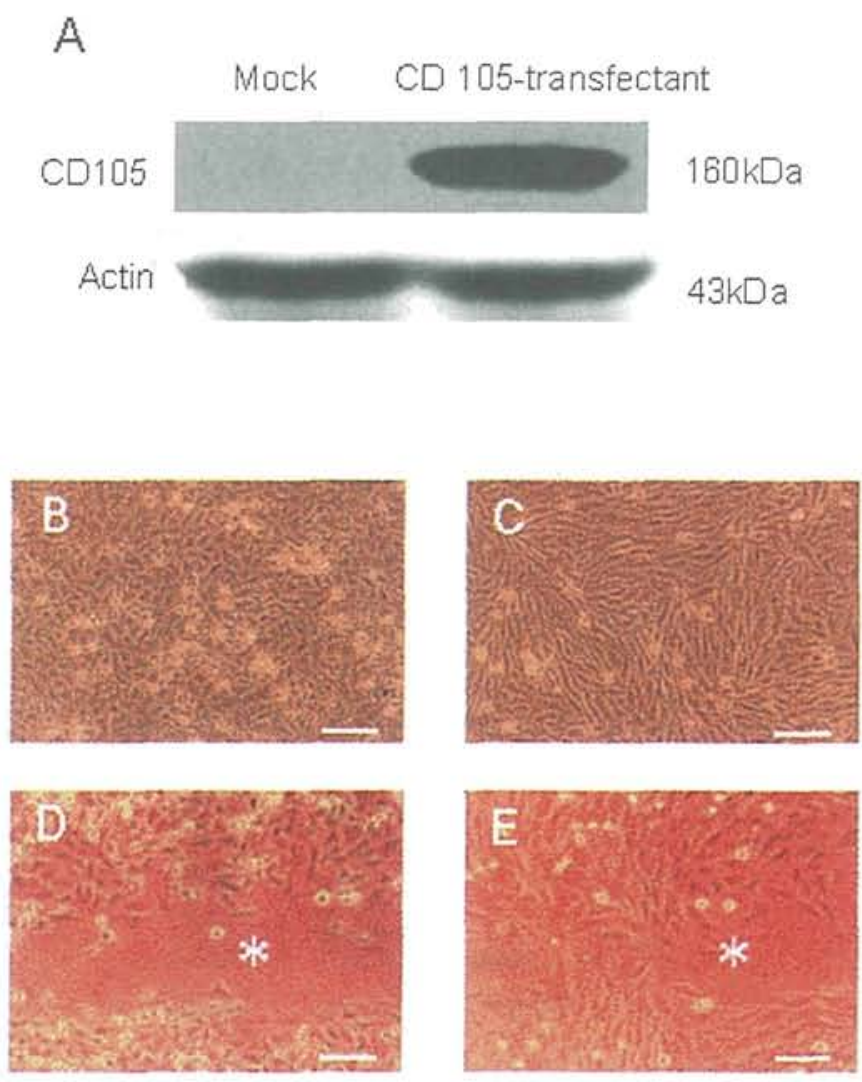

Figure 1. Expression of CD105 by CD105 transfected cells and cellular morphologies at confluence and after wounding. (A), Immunoblot showing the presence of a $160 \mathrm{kDa}$ band corresponding to S-CD105 from CD105 expressing cells. Mock-transfected cells were negative. Actin was used as a control for loading. (B), Mock-transfected cells retain a polygonal/rounded morphology whereas, (C) CD105 expressing cells are bipolar and appear to align into parallel cords. (D), Twenty-four hours following wounding, mocktransfected cells have migrated into the wound in a random manner whereas, (E) CD105 expressing cells have migrated further and as a cohort across the wound. "The wound location. Scale bars, $50 \mu \mathrm{m}$ (A and B); $40 \mu \mathrm{m}$ (C and D).

using the method of Pichard et al (21). Briefly, mock and CD105 expressing rat myoblast transfectants were seeded in $35 \mathrm{~mm}$ dishes in media and incubated for $48 \mathrm{~h}$. The cells were detached on ice in $1 \mathrm{mM}$ EDTA/PBS solution for $30 \mathrm{~min}$ (Sigma), a single cell suspension was then obtained by gently pipetting the cells. The cells were washed, treated with primary rabbit anti- $\beta 1$ integrin antibody in PBS $(2 \mu \mathrm{g} / \mathrm{ml}$, Chemicon International, Inc., Temecula, CA) for $1 \mathrm{~h}$ on ice and then washed twice with cold PBS. The cells were incubated with a secondary, FITC conjugated swine anti-rabbit antibody for $45 \mathrm{~min}$ at $4^{\circ} \mathrm{C}$ (1:40 dilution; Dako) and processed for flow cytometry using a FACScan flow cytometer (Becton Dickinson).

Indirect immunofluorescence. Mock transfected and CD105 expressing rat myoblasts and HDMECs were cultured in 8-well chamber slides at $1 \times 10^{4}$ cells/ml (Lab Tek, Naperville), and incubated overnight. On the following day, the cells were washed with PBS and fixed with cold $100 \%$ methanol for 10 min. After blocking with $10 \%$ rabbit serum (Sigma) for $30 \mathrm{~min}$, cells were incubated with the anti-CD105 mAb, E9, $(2 \mu \mathrm{g} / \mathrm{ml})$ for $1 \mathrm{~h}$, chambers were washed with PBS and treated with FITC conjugated, rabbit anti-mouse-IgG (at 1:50 dilution, Dako) for $45 \mathrm{~min}$. The stained preparations were mounted
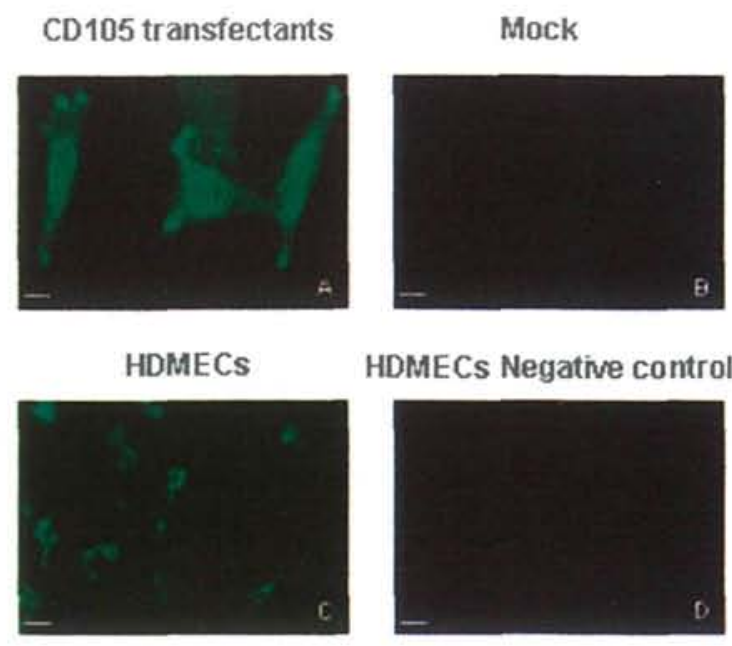

HDMECs Negative control

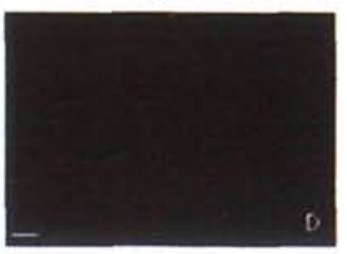

Figure 2. Distribution of CD105 on rat myoblasts and HDMECs. Cells were exposed to anti-CD105 antibody, mAb E9 and then a secondary FITC conjugated antibody. (A), CD105 expressing cells show localisation of $\mathrm{CD} 105$ at focal adhesion sites with some accumulation around the nucleus. (B), Mock-transfected cells are negative for CD105. (C), HDMEC which are known to produce CD105 also have some localisation to focal adhesion sites. (D), Negative controls. Scale bar, $1.4 \mu \mathrm{m}$.

with Citifluor (Citifluor Ltd., London), and coverslips were sealed with nail varnish then examined in a Leitz fluorescence microscope.

\section{Results}

Alteration in cell morphology and migration due to expression of CD105. All experiments were performed at least 3 times with similar results. Western blot analysis showed that CD105 transfectants displayed high expression of CD105, whereas mock cells were negative (Fig. 1A). At low cell density, mock transfectants were polygonal in morphology and tended to grow in small clusters, this polygonal morphology persisted at confluence with some evidence of multilayering and cell rounding (Fig. 1B). In contrast, CD105 expressing cells took on a bipolar fibroblastic morphology and tended to grow individually. At confluence these cells remained bipolar, often aligning in a head-to-tail fashion making parallel cords (Fig. 1C). The addition of a neutralising antibody to TGFß1 (10 $\mu \mathrm{g} / \mathrm{ml}$; R\&D Systems) had no effect on cell morphology (data not shown) indicating that morphology was not due to the presence of TGFß1.

To investigate the effect of CD105 expression on cell migration, wounding assays were set up. Briefly, mock transfectants and CD105 expressing cells were seeded in un-coated tissue culture dishes in DMEM containing 10\% FBS and G418 $(400 \mu \mathrm{g} / \mathrm{ml})$ and a wound was made using a sterile pipette tip. Over a period of $24 \mathrm{~h}$, mock cells moved into the wound in a random fashion (Fig. 1D), whereas CD105 expressing cells appeared to realign their long axis and migrate across the wound in a cohort of aligned cells (Fig. 1E).

Examination of immunofluorescence stained preparations showed that the distribution of CD105 in transfected rat myoblasts was not uniform. Using a fluorescent antibody to CD105, regions of high intensity fluorescence were observed at focal adhesion sites, most often on both apexes of polarised cells in CD105 expressing cells (Fig. 2A). A similar staining pattern 


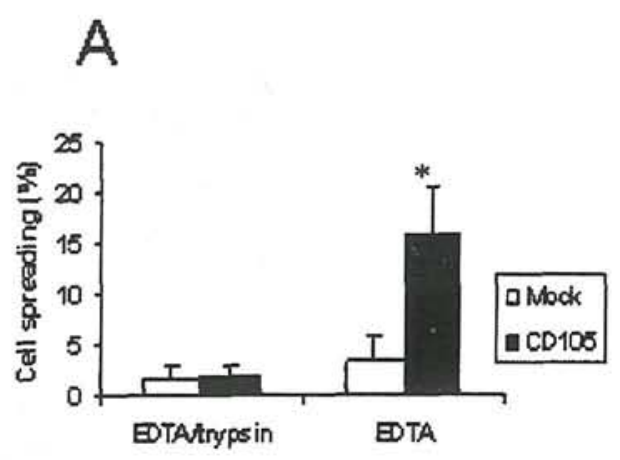

B
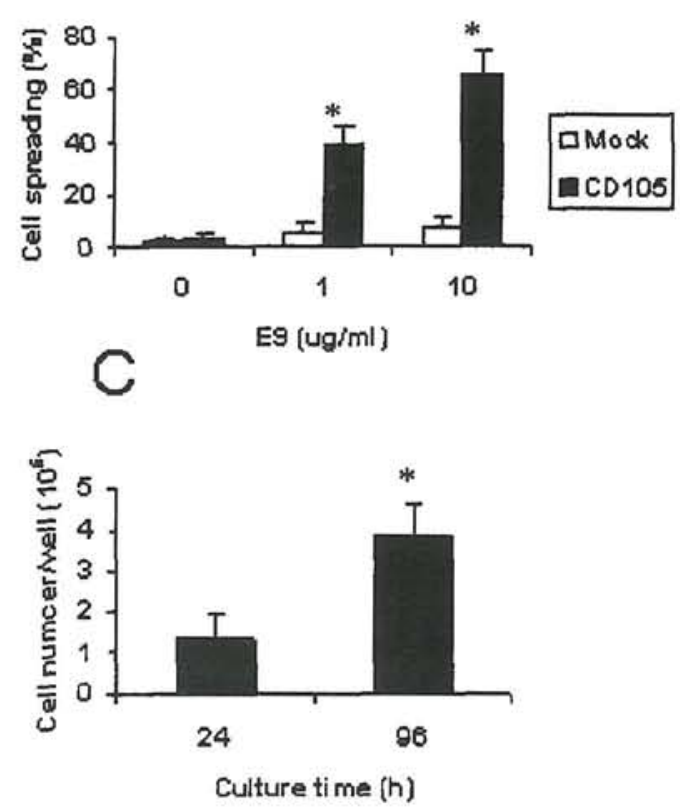

Figure 3. CD105 influences cell attachment and spreading. Cells were grown in serum-containing medium then harvested and plated out in serum-free medium. (A), When detached using EDTA solution, CD105 expressing cells were able to spread in serum-free media over a 24 -h period whereas mock cells could not. Very few cells were able to spread if detached using EDTA/trypsin solution. (B), Addition of anti-CD105 antibody E9 allowed CD105 cells to spread within $24 \mathrm{~h}$ even if detached with EDTA/trypsin. E9 antibody exhibited a concentration-dependent effect. Mock-transfected cells did not spread. (C), CD105 expressing cells, detached by EDTA/trypsin and grown in the presence of E9 antibody were able to proliferate and reach confluence by $96 \mathrm{~h}$. Mock transfected cells did not grow (data not shown). Data were obtained from triplicate readings from three separate experiments for each assay. 'SEM, $\mathrm{p}<0.01$ analysed by a one-way ANOVA followed by a Duncan's test.

was observed in HDMEC cells, which are known to express CD105 (Fig. 2C). In contrast, mock-transfected cells did not demonstrate any fluorescent staining (Fig. 2B).

CD105 expression had no effect on the morphology or the ability to adhere in the non-adherent U937 cell line (data not shown).

The effect of CDIO5 on cell attachment and spreading. In serum-free media, CD105 expressing cells (harvested either by cell scraping or by EDTA/PBS solution) were able to attach and spread within $24 \mathrm{~h}$, however, mock-transfected cells did
A

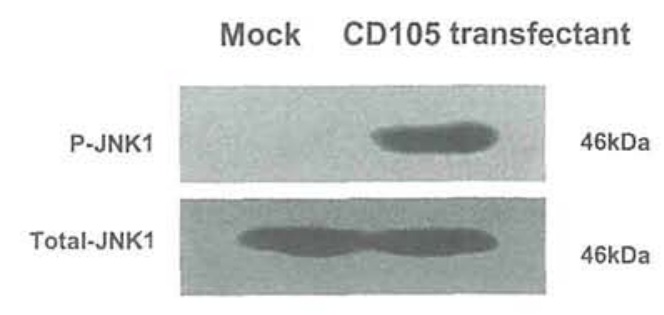

B

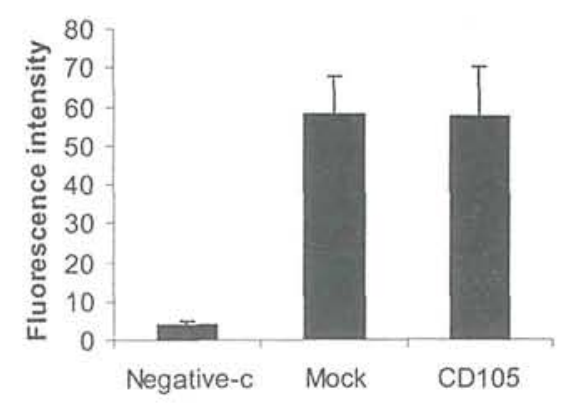

Figure 4. CD105 expression is associated with JNK1 phosphorylation but not B1 integrin up-regulation. (A), SDS-PAGE of cell lysates followed by ECL detection demonstrates the presence of phosphorylated JNK1 in CD105 expressing cells but not in mock-transfected cells. (B), CD105 expressing and mock-transfected cells were incubated with a polyclonal rabbit anti- $B 1$ integrin antibody and processed for flow cytometry. Cells were incubated with non-immune rabbit serum for controls. There was no difference in B1 integrin expression between CD105 expressing and mock-transfected cells. Data were obtained form triplicate reading from three separate experiments. Data were analysed by a one-way ANOVA followed by a Duncan's test.

not spread or grow (data not shown). Exposure to an RGDcontaining peptide inhibited CD105 cell spreading but exposure to a RAD-containing peptide had no effect (data not shown). Very little cell spreading was observed if, prior to plating out, mock-transfected or CD105 expressing cells were harvested with an EDTA/trypsin solution (Fig. 3A). This inability to spread could be reversed in CD105 expressing cells but not in mock cells by the addition of the anti-CD105 antibody, E9 in a concentration-dependent manner (Fig. 3B). A control antibody of the same isotype as E9 had no effect on either cell (data not shown). CD105 expressing cells were able to grow and proliferate in serum-free media containing E9 for $>1$ week and reach confluence (Fig. 3C). Once again, cell attachment and spreading in the presence of E9 was antagonised by a RGD but not a RAD-containing peptide (data not shown).

CD105 and cell signalling. Mock-transfected and CD105 expressing cells were grown to $\sim 80 \%$ confluency in serumcontaining medium and then transferred to serum-free medium for $24 \mathrm{~h}$, when the cells were washed, harvested and lysed. Immunoblotting analysis demonstrated that overexpression of CD105 was accompanied by phosphorylation of JNK1 (Fig. 4A) whereas flow cytometry showed no alteration in expression of B1 integrin (Fig. 4B). 


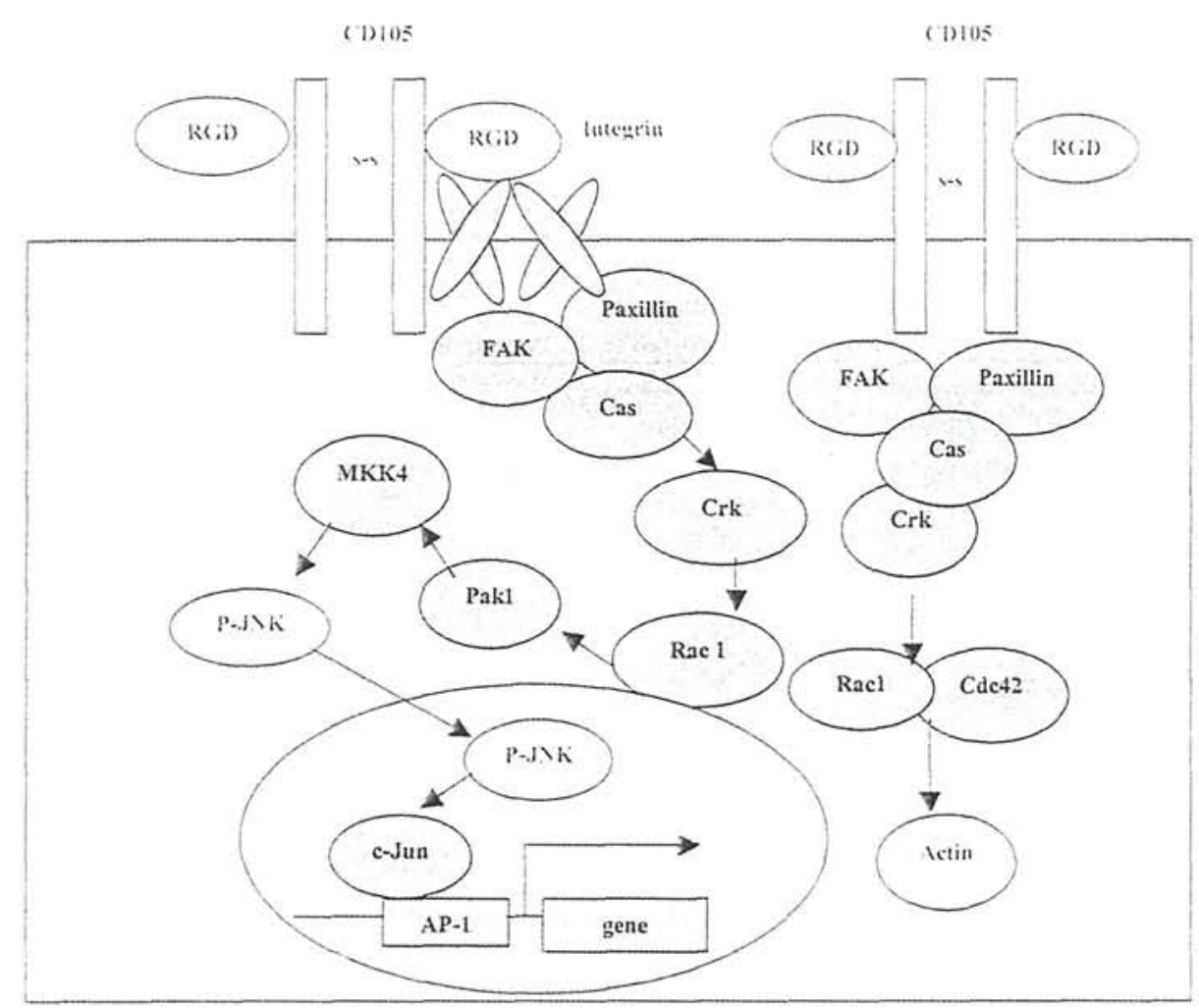

Figure 5. Diagrammatic representation of cell signalling pathways in CD105 expressing cells. CD105 could interact with integrins via its RGD sequence (left side) or directly with intracellular adapter proteins such as paxillin or P130Cas (right side) in order to influence cell morphology and survival. Adapted from refs. $23,35,45$.

\section{Discussion}

CD105 is an important component of the TGFß receptor complex but only approximately $1 \%$ of the total number of CD105 molecules are able to bind TGFß1 in ECs (6). This suggests that $\mathrm{CD} 105$ has other functions. In this report we demonstrate that CD105 expression is linked to cell adhesion, spreading and growth, it influences cellular morphology and may be localised to focal adhesion sites to aid migration. In addition, we show that CD105 expression results in phosphorylation of JNK1 - an indicator of integrin activation $(22,23)$.

Mock-transfected cells could adhere and spread to take on a polygonal morphology and grew in clusters when grown in serum-containing medium. In serum-free medium, these cells did not spread or grow. CD105 expressing cells also attached and spread in serum-containing medium where they grew as individual cells, took on a typical, bipolar, fibroblastic morphology and formed head-to-tail alignments. The expression of CD105 allowed these cells to continue to attach and retain their fibroblastic morphology in serum-free medium in the absence of any TGFB1. CD105 expressing cells were unable to move in a random manner following wounding, they manifested directionally persistent motility, which may be related to the local accumulation of CD105 in focal adhesions. The morphological changes caused by overexpression of CD105 in rat myoblasts are similar to those found in mouse fibroblasts overexpressing CD105 (24), where the cells were maintained on fibronectin or collagen-coated culture dishes.

The non-random distribution of CD105 reported here is consistent with a recent report that prostate cells transfected with CD105 showed localisation of CD105 in adhesion sites (25). These authors also noted co-localisation of CD105 with actin in the adhesion sites. Since cell morphology is determined mainly by its intracellular organisation of cytoskeletal actin and influenced by focal adhesions (26), it is reasonable to conclude that CD105 affected cell morphology in myoblasts, in this report, by interacting with molecules in focal adhesion sites.

Cellular morphology is controlled by the interaction of integrins with the protein components of focal adhesion complexes and thus, the actin cytoskeleton, producing the bipolar, fibroblastic shape (27-29). Activation of integrins occurs via a RGD-containing ligand binding to the extracellular domain of the integrin. In this report, CD105 expression did not alter the gene expression level of $B 1$ integrin, which suggests that CD105 may be activating the existing integrin via its RGD sequence on the extracellular portion of the molecule or CD105 may activate other focal adhesion components directly - as shown diagrammatically in Fig. 5. CD105 has previously been proposed as a counter-receptor for one or more members of the integrin family (18). Once activated, integrins can mediate different pathways regulating signal transduction through a focal adhesion kinase (FAK) $(30,31)$ or FAK independent Cas/Crk/Rac pathway (26) and organise the actin cytoskeleton through the small Rho-GTPase family (32). The Rho family of GTPases serve as molecular switches, transducing signals from the extracellular environment to elicit cellular responses such as changes in gene expression, morphology and migration (33).

Other cell receptors are known to activate integrins via the RGD sequence, e.g. the RGD sequence of the P2Y2 
nucleotide receptor (P2Y2R) interacts with $\alpha \mathrm{v} ß 3$ integrin and is required for $\mathrm{G}_{0}$-mediated signal transduction (34). In this report we have demonstrated that JNK is phosphorylated in CD105 expressing cells. Fig. 5 shows that JNK phosphorylation occurs after integrin activation and may occur via the FAK/ Cas/Crk/Rac/Pak1/MKK4/JNK pathway (35). Therefore we suggest that integrins are involved in CD105-related cellular responses. JNK activity is known to be elevated upon integrin aggregation $(22,36)$. Activation and phosphorylation of P130Cas has been linked to directionally persistent movement (37) as exhibited here by CD105 expressing cells following wounding. Directional cell movement plays important roles during wound healing, angiogenesis and immune function (38). The movement of ECs, smooth muscle cells and macrophages, all of which have significantly increased levels of CD105 (1,2,39-41), may be important in these processes.

Cell spreading is closely linked to cell survival and growth $(42,43)$. The cell spreading observed when CD105 expressing cells were grown in serum-free medium was directly linked to the presence of the RGD sequence in the CD105 since it could be antagonised by a RGD peptide but not a RAD peptide. Mock-transfected cells, which did not express CD105, were considerably easier to detach from the tissue culture surface, even in the presence of serum. The anti-CD105 mAb, E9, markedly promoted cell spreading and growth of CD105 expressing cells on uncoated plastic dishes in serum-free medium. Once again, this effect was blocked by a RGD but not a RAD-containing peptide. Anti-CD105 mAbs (44G4 and 29-G8) have been reported to stimulate the proliferation of foetal bone marrow stromal cells in medium with $10 \%$ FCS (44). Treatment of HUVEC monolayers with a panel of anti-CD105 mAbs has been observed to result in a 5- to 10fold increase in adhesion of U937 cells to HUVECs. This adhesion can be inhibited by a RGD-containing hexapeptide (18). The adhesion is believed to be due to interactions between integrin and the RGD sequence of the CD105, a similar observation to that reported here. The exact role played by anti-CD105 antibodies remains unclear but it is possible that the binding of the anti-CD105 mAb to CD105 leads to a conformational change in CD105 which then allows the RGD sequences on the CD105 extracellular domain to fully bind and activate $\beta 1$ integrin.

CD105 may be able to activate the actin cytoskeleton through a pathway which does not involve integrins. The integrin subunit $B 1$ is a transmembrane protein which consists of a large extracellular domain, a single transmembrane stretch, and a short intracellular cytoplasmic domain (36). CD105 is also a transmembrane glycoprotein with a large extracellular domain and a short intracellular cytoplasmic domain. The structure of CD105 is similar to B1 integrin. Therefore CD105 may be able to regulate the organisation of the actin cytoskeleton by interacting directly with the Rho-family of proteins and adaptor proteins, such as paxillin and P130Cas and as such influence cell morphology (Fig. 5).

In summary, overexpression of CD105 in rat myoblasts leads to a transition of cell morphology from a polygonal shape to a fibroblast-like elongated form. An immunofluorescence study demonstrated that CD105 resided in the focal adhesion complex. CD105 expressing cells exhibited cell polarity. The cells were able to attach and spread in serum-free medium and anti-CD105 mAb, E9, enhanced this effect. Spreading was blocked by the addition of a RGD peptide. We suggest that $\mathrm{CD} 105$, in addition to having a role as a TGFß receptor, has a major role in influencing cell adhesion, migration and survival.

\section{References}

1. Lastres P, Bellon T, Cabanas C, Sanchez-Madrid F, Acevedo A, Gougos A, Letarte $M$ and Bernabeu C: Regulated expression on human macrophages of endoglin, an Arg-Gly-Asp-containing surface antigen. Eur J Immunol 22: 393-397, 1992.

2. O'Connell PJ, McKenzie A, Fisicaro N, Rockman SP, Pearse MJ and D'Apice AJ: Endoglin: a 180-kDa endothelial cell and macrophage restricted differentiation molecule. Clin Exp Immunol 90: 154-159, 1992

3. Li CG, Wilson PB, Bernabeu C, Raab U, Wang JM and Kumar S: Imunodetection and characterisation of soluble CD105-TGFß complexes. J Immunol Methods 218: 85-93, 1998.

4. Li CG, Guo B, Bernabeau C and Kumar S: Angiogenesis in breast cancer: the role of transforming growth factor $B$ and CD105. Microsc Res Tech 52: 437-449, 2001.

5. Li DY, Sorensen LK, Brooke BS, Urness LD, Davis EC, Taylor DG, Boak BB and Wendel DP: Defective angiogenesis in mice lacking endoglin. Science 284: 1534-1537, 1999.

6. Cheifetz S, Bellon T, Cales C, Vera S, Bernabeu C, Massague J and Letarte M: Endoglin is a component of the transforming growth factor-beta receptor system in human endothelial cells. J Biol Chem 267: 19027-19030, 1992.

7. St Jacques S, Forte M, Lye SJ and Letarte M: Localization of endoglin, a transforming growth factor-beta binding protein, and of CD44 and integrins in placenta during the first trimester of pregnancy. Biol Reprod 51: 405-413, 1994.

8. Qu R, Silver MM and Letarte M: Distribution of endoglin in early human development reveals high levels on endocardial cushion tissue mesenchyme during valve formation. Cell Tissue Res 292: 333-343, 1998 .

9. Kumar P, Wang JM and Bernabeu C: CD 105 and angiogenesis. J Pathol 178: 363-366, 1996.

10. Bodey B, Bodey B Jr, Siegel SE and Kaiser HE: Overexpression of endoglin (CD105): a marker of breast carcinomainduced neovascularization. Anticancer Res 18: 3621-3628, 1998.

11. Van de Kerkhof PC, Rulo HF, van Pelt JP, Vlijmen-Willems IM and De Jong EM: Expression of endoglin in the transition between psoriatic uninvolved and involved skin. Acta Derm Venereol 78: 19-21, 1998.

12. Kumar S, Ghellal A, Li C, Byrne G, Haboubi N, Wang JM and Bundred N: Breast carcinoma: vascular density determined using CD105 antibody correlates with tumour prognosis. Cancer Res 59: 856-861, 1999.

13. Brekken RA, Li C and Kumar S: Strategies for vascular targeting in tumors. Int J Cancer 100: 123-130, 2002.

14. Seon BK and Kumar S: CD105 antibody for targeting of tumour vascular endothelial cells. In: The New Angiotherapy. Fan T-P and Kohn EC (eds). Humana Press Inc., Totowa, NJ, pp499-515, 2002.

15. Arthur HM, Ure J, Smith AJ, Renforth G, Wilson DI, Torsney E, Charlton R, Parums DV, Jowett T, Marchuk DA, Burn J and Diomond AG: Endoglin, an ancillary TGFbeta receptor, is required for extraembryonic angiogenesis and plays a key role in heart development. Dev Biol 217: 42-53, 2000

16. Shovlin CL and Letarte M: Hereditary hemorrhagic telangiectasia and pulmonary arteriovenous malformations: issues in clinical management and review of pathogenic mechanisms. Thorax 54: 714-729, 1999.

17. Letamendia A, Lastres P, Botella LM, Raab U, Langa C, Velasco B, Attisano L and Bernabeu C: Role of endoglin in cellular responses to transforming growth factor-beta. A comparative study with betaglycan. J Biol Chem 273: 33011-33019, 1998.

18. Gougos A, St Jacques S, Greaves A, O'Connell PJ, D'Apice AJ, Buhring HJ, Bernabeu C, van Mourik JA and Letarte M: Identification of distinct epitopes of endoglin, an RGD-containing glycoprotein of endothelial cells, leukemic cells, and syncytiotrophoblasts. Int Immunol 4: 83-92, 1992

19. Lastres P, Letamendia A, Zhang H, Rius C, Almendro N, Raab U, Lopez LA, Langa C, Fabra A, Letarte $M$ and Bernabeu C: Endoglin modulates cellular responses to TGFß1. J Cell Biol 133: 1109-1121, 1996. 
20. Hordijk PL, Ten Klooster JP, van der Kammen RA, Michiels F, Oomen LC and Collard JG: Inhibition of invasion of epithelial cells by Tiam1-Rac signalling. Science 278: 1464-1466, 1997.

21. Pichard V, Honore S, Kovacic H, Li C, Prevot C, Briand C and Rognoni JB: Adhesion, actin cytoskeleton organisation and the spreading of colon adenocarcinoma cells induced by EGF are mediated by alpha2betal integrin low clustering through focal adhesion kinase. Histochem Cell Biol 116: 337-348, 2001.

22. Miyamoto S, Teramoto H, Coso OA, Gutkind JS, Burbelo PD, Akiyama SK and Yamada KM: Integrin function: molecular hierarchies of cytoskeletal and signalling molecules. J Cell Biol 131: 791-805, 1995.

23. Almeida EA, Ilic D, Han Q, Hauck CR, Jin F, Kawakatsu H, Schlaepfer DD and Damsky CH: Matrix survival signaling: from fibronectin via focal adhesion kinase to c-Jun $\mathrm{NH}(2)$ terminal kinase. J Cell Biol 149: 741-754, 2000.

24. Guerrero-Esteo M, Lastres P, Letamendia A, Perez-Alvarez MJ, Langa C, Lopez LA, Fabra A, Garcia-Pardo A, Vera S, Letarte M and Bernabeu C: Endoglin overexpression modulates cellular morphology, migration, and adhesion of mouse fibroblasts. Eur J Cell Biol 78: 614-623, 1999.

25. Liu Y, Jovanovic B, Pins M, Lee C and Bergan RC: Over expression of endoglin in human prostate cancer suppresses cell detachment, migration and invasion. Oncogene 21: 8272-8281, 2002.

26. Schoenwaelder SM and Burridge K: Bidirectional signalling between the cytoskeleton and integrins. Curr Opin Cell Biol 11: 274-286, 1999.

27. Juliano RL and Haskil LS: Signal transduction from the extracellular matrix. J Cell Biol 120: 577-585, 1993.

28. Clark EA and Brugge JS: Integrins and signal transduction pathways: the road taken. Science 268: 233-239, 1995.

29. Gimond C, van der Flier A, van Delft S, Brakebusch C, Kuikman I, Collard JG, Fassler R and Sonnenberg A: Induction of cell scattering by expression of betal integrins in beta1deficient epithelial cells requires activation of members of the rho family of GTPases and downregulation of cadherin and catenin function. J Cell Biol 147: 1325-1340, 1999.

30. Hanks SK and Polte TR: Signaling through focal adhesion kinase. Bioessays 19: 137-145, 1997.

31. Schlaepfer DD, Hauck CR and Sieg DJ: Signalling through focal adhesion kinase. Prog Biophys Mol Biol 71: 435-478, 1999.

32. Ridley AJ and Hall A: The small GTP-binding protein rho regulates the assembly of focal adhesions and actin stress fibers in response to growth factors. Cell 70: 389-399, 1992.

33. Hall A: Rho GTPases and the actin cytoskeleton. Science 279: 509-514, 1998.
34. Erb L, Liu J, Ockerhausen J, Kong Q, Garrad RC, Griffin K, Neal C, Krugh B, Santiago-Perez LI, Gonzalez FA, Gresham HD, Turner JT and Weisman GA: An RGD sequence in the P2Y(2) receptor interacts with alpha(V)beta(3) integrins and is required for $\mathrm{G}(\mathrm{o})$-mediated signal transduction. J Cell Biol 153: 491-501. 2001.

35. Dolfi F, Garcia-Guzman M, Ojaniemi M, Nakamura H, Matsuda M and Vuori K: The adaptor protein Crk connects multiple cellular stimuli to the JNK signaling pathway. Proc Natl Acad Sci USA 95: 15394-15399, 1998.

36. Giancotti FG and Ruoslahti E: Integrin signalling. Science 285: 1028-1032, 1999.

37. Gu J, Tamura M, Pankov R, Danen EH, Takino T, Matsumoto K and Yamada KM: Shc and FAK differentially regulate cell motility and directionality modulated by PTEN. J Cell Biol 146: 389-403, 1999.

38. Laukaitis CM, Webb DJ, Donais K and Horwitz AF: Differential dynamics of alpha 5 integrin, paxillin, and alpha-actinin during formation and disassembly of adhesions in migrating cells. J Cell Biol 153: 1427-1440, 2001.

39. Gougos A and Letarte M: Primary structure of endoglin, an RGD-containing glycoprotein of human endothelial cells. J Biol Chem 265: 8361-8364, 1990.

40. Adam PJ, Clesham GJ and Weissberg PL: Expression of endoglin mRNA and protein in human vascular smooth muscle cells. Biochem Biophys Res Commun 247: 33-37, 1998.

41. Re F, Zanetti A, Sironi M, Polentarutti N, Lanfrancone L, Dejana E and Colotta F: Inhibition of anchorage-dependent cell spreading triggers apoptosis in cultured human endothelial cells. J Cell Biol 127: 537-546, 1994.

42. Conley BA, Smith JD, Guerrero-Esteo M, Bernabeu C and Vary CP: Endoglin, a TGF-beta receptor-associated protein, is expressed by smooth muscle cells in human atherosclerotic plaques. Atherosclerosis 153: 323-335, 2000.

43. Chen CS, Mrksich M, Huang S, Whitesides GM and Ingber DE: Geometric control of cell life and death. Science 276: 1425-1428, 1997.

44. Rokhlin OW, Cohen MB, Kubagawa $\mathrm{H}$, Letarte $\mathrm{M}$ and Cooper MD: Differential expression of endoglin on fetal and adult hematopoietic cells in human bone marrow. J Immunol 154: 4456-4465, 1995.

45. Tanaka S, Ouchi T and Hanafusa H: Downstream of Crk adaptor signalling pathway: activation of Jun kinase by v-Crk through the guanine nucleotide exchange protein C3G. Proc Natl Acad Sci USA 94: 2356-2361, 1997. 